\title{
PENSAMIENTOS DIVERSOS SOBRE EUROPA, SU GENTE Y MIGRACIÓN
}

\author{
Nenad HLaČA ${ }^{1 *}$ \\ Profesor de la Universidad de Rijeka \\ E-mail: nenad.hlaca@pravri.hr
}

\begin{abstract}
RESÚMEN: Europa vista como el destino de los inmigrantes es, por supuesto, sólo una cara de la moneda que estamos viendo en la actualidad, de una parte, y de otra, la movilidad de ciudadanos eruopeos que cambian de residencia para habitar en Estados que no son los de su nacionalidad. Todo ello se muestra con datos que finalizan en con un análisis positivo de la UE, promoviendo el movimiento transfronterizo de personas a través de su libre movimiento de personas como una de sus libertades fundamentales y otras políticas e instrumentos, también haya tomado medidas para ayudar a las parejas transfronterizas. en caso de que su relación falle.
\end{abstract}

Palabras clave: migración, familias transfronterizas, Unión europea.

ABSTRACT: Europe seen as the destination of migrants is, of course, only one side of the coin that we are currently seeing, on the one hand, and on the other, the mobility of European citizens who change their residence to live in states other than those of their nationality. All this is shown with data ending in a positive analysis of the EU, by promoting the cross-border movement of persons through its free movement of persons as one of its fundamental freedoms and other policies and instruments, has also taken measures to help cross-border couples. in case their relationship fails.

Keywords: migration, cross-border families, European Union.

SUMARIO: I. HISTORIA EUROPEA DE LA MIGRACIÓN. II. RETOS ACTUALES DE LA MIGRACIÓN PARA LA UNIÓN EUROPEA. III. RETOS ACTUALES DE LA MIGRACIÓN PARA LA UNIÓN EUROPEA. IV. MIGRACIÓN Y FAMILIAS TRANSFRONTERIZAS

\section{HISTORIA EUROPEA DE LA MIGRACIÓN}

Desde el principio, la migración es el estado constante de los seres humanos². Desde la etapa inicial cuando los predecesores del homo sapiens poblaban el mundo hasta los tiem-

1 * Traducido por Fátima Pérez Ferrer, profesora titular de Derecho Penal de la Universidad de Almería.

2 Reconocido también por las instituciones de la UE. Véase, por ejemplo, Comisión Europea, Comunicación de la Comisión sobre un nuevo pacto sobre migración y asilo, Bruselas, 23.9.2020, COM (2020) 609 final. 
pos modernos, cuando las oleadas de migrantes, la migración nunca se detuvo. Si bien los motivos en la prehistoria eran la búsqueda de un mejor clima, recursos naturales y condiciones de cultivo de alimentos, en los tiempos modernos las migraciones son impulsadas por la industrialización, la política o consideraciones laborales / del mercado. Cualquiera que sea el caso, los seres humanos están en una búsqueda constante de mejores condiciones, y Europa no es una excepción. En realidad, son las continuas migraciones las que crearon tanto Europa como lo que llamamos una civilización "occidental".

Curiosamente, la etimología de la palabra 'Europa' ha sido discutida vívidamente por lingüistas históricos con la ayuda de antropólogos, arqueólogos, historiadores genéticos, historiadores demográficos, etnohistoriadores, historiadores de la literatura y el arte,

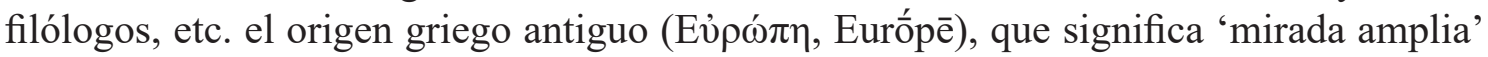
y relacionado con el nombre de la princesa fenicia mítica secuestrada por el gran dios Zeus a la antigua raíz sumeria y semítica de la palabra 'Ereb' (בְרָּ, eh'-reb ), que significa 'oscuridad' o 'descenso' desde la perspectiva de la ubicación occidental de la región en relación con el Medio Oriente. Por lo tanto, se puede encontrar una explicación de que se refería a la "tierra donde se pone el sol". Algunos de los muchos significados de la palabra "Ereb" en lenguas semíticas incluyen también desierto, nómada, nómada, comerciante, moverse. Por tanto, etimológicamente, Europa es también el último paso de las migraciones de este a oeste. Frente a la tierra del sol naciente, Europa es la tierra de tarde y puesta del sol: el final del día, o también podría decirse el final de los flujos migratorios.

La migración está influenciada por una combinación de factores económicos, ambientales, políticos y sociales: ya sea en el país de origen del migrante (factores de empuje) o en el país de destino (factores de atracción). Históricamente, se cree que la relativa prosperidad económica y la estabilidad política de la UE han ejercido un considerable efecto de atracción sobre los inmigrantes ${ }^{3}$. Aunque a algunos les pueda parecer que ahora nos enfrentamos a migraciones sin precedentes, es un hecho que las migraciones son el núcleo de la identidad de los europeos. A lo largo de la historia, Europa ha sido atractiva para muchos, incluidas las migraciones de guerreros primero del pueblo celta y más tarde de las tribus bárbaras, así como las migraciones coloniales y poscoloniales a algunos países europeos.

Europa vista como el destino de los inmigrantes es, por supuesto, sólo una cara de la moneda que estamos viendo en la actualidad. Así como Europa invitaba a millones a venir y habitarla, constantemente a lo largo de la historia de la humanidad millones emigraron de Europa. Mirar el otro lado de lo mismo podría recordar el hecho de que las emigraciones desde Europa se han producido desde la época de los antiguos griegos que crearon muchas colonias en el Mediterráneo, hasta la Edad Media, cuando millones de europeos se trasladaron a América tras su descubrimiento. en 1492 ya América, Australia y Nueva Zelanda, especialmente en los siglos XIX y XX.

\section{RETOS ACTUALES DE LA MIGRACIÓN PARA LA UNIÓN EUROPEA}

Las políticas de migración dentro de la UE se han preocupado cada vez más por atraer un perfil migratorio particular, a menudo en un intento de aliviar la escasez de habilidades

3 E. BALABANOVA, A. BLACH, "Envío y recepción. El marco ético de la migración dentro de la UE en la prensa europea », European Journal of Communication, 2010, vol. 25, no. 4, págs. 382-397. 
específicas ${ }^{4}$. Además de las políticas para fomentar la contratación laboral, la política de inmigración se centra a menudo en dos áreas adicionales: prevenir la migración no autorizada y el empleo ilegal de migrantes que no tienen permiso para trabajar, así como promover la integración de los inmigrantes en la sociedad. Se han movilizado importantes recursos para luchar contra las redes de tráfico y trata de personas en la UE.

Las cifras de migración en la UE son notablemente altas. Según Eurostat ${ }^{5}$, el 1 de enero de 2020, 23 millones de personas (5,1\%) de los 447,3 millones de personas que viven en la UE eran ciudadanos de fuera de la UE. Un total de 4,2 millones de personas inmigraron a uno de los Estados miembros de la UE durante 2019, mientras que se informó que 2,7 millones de emigrantes habían abandonado un Estado miembro de la UE. Sin embargo, estas cifras totales no representan los flujos migratorios hacia / desde la UE en su conjunto, ya que también incluyen los flujos entre los diferentes Estados miembros de la UE. En 2019, se estimaba que había 2,7 millones de inmigrantes en la UE de países no pertenecientes a la UE, y aproximadamente 1,2 millones de personas emigraron de la UE a un país fuera de la UE. Además, 1,4 millones de personas que anteriormente residían en un Estado miembro de la UE emigraron a otro Estado miembro de la UE.

Alemania reportó el mayor número total de inmigrantes (886,3 mil) en 2019, seguida de España (750,5 mil), Francia (385,6 mil) e Italia (332,8 mil). Alemania también reportó el mayor número de emigrantes en 2019 (576,3 mil), seguida de Francia (299,1 mil), España (296,2 mil) y Rumanía (233,7 mil). Un total de 22 de los Estados miembros de la UE notificaron más inmigración que emigración en 2019. Sin embargo, en Bulgaria, Croacia, Letonia, Dinamarca y Rumanía, el número de emigrantes superó en número al de inmigrantes.

La información sobre ciudadanía se ha utilizado a menudo para investigar sobre inmigrantes de origen extranjero. Sin embargo, dado que la ciudadanía puede cambiar a lo largo de la vida de una persona, también es útil analizar la información sobre el país de nacimiento. La proporción relativa de inmigrantes autóctonos dentro del número total de inmigrantes fue mayor en Bulgaria (59\% de todos los inmigrantes), seguida de Rumanía (49\%) y Lituania (46\%). Por el contrario, Luxemburgo y España informaron proporciones relativamente bajas de inmigrantes nativos, el 5\% o menos de toda la inmigración en 2019.

Un análisis de la residencia anterior revela que Luxemburgo registró la mayor proporción de inmigrantes procedentes de otro Estado miembro de la UE (91\% de su número total de inmigrantes en 2019), seguido de Austria (63\%) y Eslovaquia (60\%); España y Eslovenia comunicaron porcentajes relativamente bajos (ambos del 16\%). En cuanto a la distribución por sexo de los inmigrantes a los Estados miembros de la UE en 2019, había un poco más de hombres que de mujeres (54\% en comparación con 46\%). El Estado miembro de la UE que informó la mayor proporción de inmigrantes varones fue Croacia (77\%); por el contrario, la mayor proporción de mujeres inmigrantes se registró en Chipre (53\%). La mitad de los inmigrantes tenían menos de 29 años. Los inmigrantes

4 R. ORŁOWSKA, 'La inmigración en la Unión Europea en la segunda década del siglo XXI: ¿problema o solución?’ (2011) Folia Oeconomica Stetinensia 10 (1), disponible en $<$ https://sciendo.com/article/10.2478/ v10031-011$\underline{0015-0}>(1.8 .2021)$.

5 Véanse los datos de Eurostat disponibles en <https:/ec.europa.eu/eurostat/statisticsexplained/index.php/ Migration and migrant population statistics\#column-one Estadísticas de migración y población migrante: datos extraídos en marzo de 2021> (24.4.2021). 
en los Estados miembros de la UE en 2019 eran, en promedio, mucho más jóvenes que la población total que ya residía en el país de destino. El 1 de enero de 2020, la edad media de la población total de la UE era de 43,9 años, mientras que para los inmigrantes en 2019 era de 29,2 años.

El número de personas que residían en la UE con la ciudadanía de un país tercero a 1 de enero de 2020 era de 23 millones, lo que representa el 5,1\% de la población de la UE. Además, 13,5 millones de personas vivían en uno de los Estados miembros de la UE el 1 de enero de 2020 con la ciudadanía de otro Estado miembro de la UE. En términos absolutos, el mayor número de no nacionales que vivían en los Estados miembros de la UE a 1 de enero de 2020 se registró en Alemania (10,4 millones de personas), España (5,2 millones), Francia (5,1 millones) e Italia (5,0 millones de personas). Los no nacionales en estos cuatro Estados miembros de la UE representaron colectivamente el $71 \%$ del número total de no nacionales que vivían en todos los Estados miembros de la UE juntos, mientras que los mismos cuatro Estados miembros de la UE tenían una participación del $58 \%$ de la población de la UE.

El 1 de enero de 2020, Bélgica, Irlanda, Luxemburgo, Austria y Eslovaquia eran los Estados miembros de la UE donde los no nacionales que vivían en esos estados eran principalmente ciudadanos de otro Estado miembro de la UE. Esto significa que en la mayoría de los Estados miembros de la UE, la mayoría de los no nacionales eran ciudadanos de países no pertenecientes a la UE. En Letonia y Estonia, la proporción de ciudadanos de países terceros es considerable debido al elevado número de no ciudadanos, principalmente ciudadanos de la ex Unión Soviética, que residen permanentemente en estos países pero no han adquirido ninguna otra ciudadanía.

En términos relativos, el Estado miembro de la UE con la mayor proporción de no nacionales fue Luxemburgo, ya que los no nacionales representaban el 47\% de su población total. También se observó una alta proporción de ciudadanos extranjeros (más del 10\% de la población residente) en Malta, Chipre, Austria, Estonia, Letonia, Irlanda, Alemania, Bélgica y España. Por el contrario, los no nacionales representaban menos del 1\% de la población en Polonia $(0,9 \%)$ y en Rumanía $(0,7 \%)$. La proporción relativa de nacidos en el extranjero dentro de la población total fue más alta en Luxemburgo ( $48 \%$ de la población residente), seguida de Malta (23\%) y Chipre (22\%). Por el contrario, Polonia registró la proporción más baja de nacidos en el extranjero, solo el $2 \%$ de su población total, el 1 de enero de 2020 , seguida de Bulgaria (2,7\%), Eslovaquia (3,6\%) y Rumanía (3,7\%).

Los ciudadanos rumanos, polacos, italianos y portugueses fueron los cuatro grupos más importantes de ciudadanos de la UE que vivían en los demás Estados miembros de la UE en 2020. Un análisis de la estructura de edad de la población indica que, para la UE en su conjunto, la población extranjera era más joven que la población nacional. La distribución de los extranjeros por edad, en comparación con los nacionales, muestra una proporción más significativa de adultos relativamente jóvenes en edad de trabajar. El 1 de enero de 2020, la edad media de la población nacional en la UE era de 45 años, mientras que la edad media de los no nacionales que vivían en la UE era de 36 años. Como se desprende de estas cifras, aunque se limita solo a 2019, la UE se enfrenta simultáneamente a dos tipos de migraciones: internas y externas. Los ciudadanos de los Estados miembros de la UE tienen la libertad de viajar y la libertad de movimiento dentro de las fronteras internas de la UE. Estas migraciones dentro de la UE han afectado a las economías y sociedades 
de los Estados miembros, tanto de los Estados miembros predominantemente inmigrantes como de los emigrantes predominantes. Con casi cada ola de ampliación hubo trayectorias migratorias acompañantes. Lo mismo ocurre con el Brexit: en el intento de neutralizar la disminución de la inmigración en la UE tras el Brexit, el gobierno del Reino Unido parece haber ajustado la política de inmigración fuera de la $\mathrm{UE}^{6}$. Como resultado, las sociedades europeas son, en la actualidad, y también lo serán en el futuro, cada vez más diversas. La UE apoya realmente el fenómeno de la migración dentro de la UE mediante la variedad de sus políticas e instrumentos, además de la piedra angular de la libertad de circulación garantizada por los Tratados Fundacionales. Algunos de estos instrumentos también se tratan en este volumen y tienen como objetivo consolidar las normas de los Estados miembros en beneficio de los ciudadanos de la UE y las personas que residen en la UE siempre que su propiedad familiar tenga implicaciones transfronterizas ${ }^{7}$.

La mención de la migración exterior recuerda instantáneamente en la mente de muchos europeos las imágenes de numerosos inmigrantes de terceros países, que llegaron a la Unión Europea en grandes oleadas en 2015 y provocaron una grave "crisis migratoria". De hecho, fue una respuesta desesperada a la necesidad de rejuvenecer la fuerza de trabajo que fue creada por las tendencias demográficas negativas en la UE. De hecho, los Estados miembros son demográficamente viejos y algunos experimentan una fuerte disminución de la población. Las predicciones para el futuro también son muy pesimistas, a menos que los Estados miembros se esfuercen lo suficiente por diseñar una política migratoria global y eficaz ${ }^{8}$.

A pesar del impacto positivo en la economía del Estado miembro de acogida, en ocasiones se percibe que las migraciones amenazan la identidad y la cultura del país de acogida. Si bien la UE toma medidas para coordinar las políticas migratorias intensivas de la Unión Europea ${ }^{9}$, tales intentos parecen tener un efecto limitado. Los Estados miembros todavía difieren en gran medida en muchos aspectos que son relevantes para el desarrollo de los procesos migratorios. Se encuentran en diferentes grados de desarrollo económico; tienen diferentes niveles de multiculturalismo de sus sociedades; sus políticas nacionales de inmigración y su marco regulatorio difieren; algunos tienen muchos inmigrantes asentados de etapas anteriores de la migración, mientras que otros tienen una pequeña población de inmigrantes. Estas y otras circunstancias se atribuyen al atractivo de un Estado miembro en particular sobre otros Estados miembros para los migrantes, solicitantes de asilo y refugiados. Por estas razones, solo varios Estados miembros tienden a ser destinos deseables para los inmigrantes; mientras que los demás, normalmente Estados miembros menos prósperos, no pueden mantener a su propia población, y mucho menos a los inmigrantes.

Estas olas migratorias intensificaron las tensiones ideológicas entre el valor del humanismo universal y el utilitarismo centrado en la nación. La crisis también afectó

6 J. PORTES, "Immigration and the UK economy after Brexit", IZA DP No. 14425, mayo de 2021, accesible en

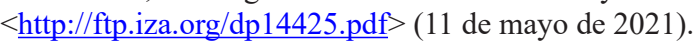

7 Ver 4 en este Capítulo.

8 Ver p. Ej. G. ZBIŃKOWSKI, "Migrant Crisis in the EU and its Demographic Context Directions of Poland's Migration Policy After 2018”, Przeglad Zachodni, vol. 373, no. 4, 2019, págs. 91-106; M. JERIĆ, "Emigración contemporánea de croatas: ¿Cuál es el futuro de la República de Croacia?”, Oeconomica Jadertina, vol. 9, núm. 2, 2019, págs. 21-31.

9 Véase Timeline - European Union Migration Policy, accesible en $<\underline{\text { https://www.consilium.europa.eu/en/policies/ }}$ eu-migration-policy/migration-timeline/> (21 de junio de 2021). 
duramente a la solidaridad entre los Estados miembros de la Unión Europea y dio lugar a muchos intentos institucionales y legislativos para reformar el sistema, entre los que destaca el Nuevo Pacto sobre Migración y Asilo, anunciado por la Comisión Europea en septiembre de 2020. un sistema genuino y completo para coordinar las acciones de los Estados miembros en las políticas de inmigración. Se ha descrito como un edificio de tres plantas en el que todos los niveles deben ser igualmente estables y fiables. El primer piso es la dimensión externa, destinada a desarrollar las relaciones con unos 25 países de origen y a incidir en el tránsito de migrantes y solicitantes de asilo para que no tengan la necesidad de salir. El segundo piso se refiere a la gestión de las fronteras exteriores de la UE, que sería una responsabilidad común y compartida, no solo de los Estados miembros de la primera entrada. Implicaría el refuerzo de Frontex, la Agencia Europea de la Guardia de Fronteras y Costas, los procedimientos de control obligatorios y los mecanismos de retorno eficaces. El tercer piso formaría un nuevo sistema en el que los mecanismos de solidaridad y distribución de la carga serían factores clave para lograr la eficiencia del sistema genera $1^{10}$. Queda por ver con qué éxito se llevará a cabo este Plan, especialmente en vista de su programa muy ambicioso.

Sea cual sea su origen, otro Estado miembro de la UE o un tercer país, los inmigrantes participan en el proceso de aculturación más o menos intenso. Cuanto más diferente es el entorno social y cultural en el país de origen, más difícil y duradero es el proceso de aculturación. Como desarrollo multidimensional, este proceso implica la adopción de nuevos valores y el cambio de viejos hábitos, para eventualmente resultar en la formación de nuevas identidades. Los cambios en la condición social de los migrantes pueden adoptar diferentes formas, desde la marginación y la estigmatización hasta la asimilación y la plena integración en la sociedad y la cultura de acogida ${ }^{11}$. A menos que los migrantes adopten la compleja realidad pública y política del nuevo país de acogida, no podrán integrarse funcionalmente en su nuevo hábitat. En ocasiones las escuelas, las asociaciones religiosas, los clubes culturales o incluso deportivos en los que predomina la mayoría de la patria ofrecen una importante sensación de seguridad y ayudan a superar el turbulento período de adaptación. Sin embargo, si los inmigrantes permanecen así aislados, incluso muchos años después, los de la primera generación de inmigrantes siguen siendo ciudadanos divididos ${ }^{12}$. Al darse cuenta de la gravedad de las amenazas al funcionamiento interno no solo de los Estados miembros, sino también de la UE en su conjunto, el Consejo de la Unión Europea formuló recomendaciones sobre la integración de los nacionales de terceros países que residen legalmente en la $\mathrm{UE}^{13}$. Esto se suma a las comunicaciones anteriores de la Comisión Europea tituladas "Plan de acción para la

10 Margaritis Schinas, vicepresidenta de la Comisión Europea, 'Check against delivery', discurso del vicepresidente Schinas sobre el nuevo pacto sobre migración y asilo, Bruselas, 23 de septiembre de 2020, accesible en $<\underline{\text { https: } / /}$ ec.europa.eu/commission/presscorner/detail/es/SPEECH_20_1736> (11 de mayo de 2021); Margaritis Schinas, vicepresidenta de la Comisión Europea, discurso de apertura en el seminario web sobre el nuevo pacto, organizado por el King's College de Londres y el Instituto Británico de Derecho Internacional y Comparado, el 22 de abril de 2021.

11 A. NYLUND, "Revisión de las" construcciones discursivas de la identidad en la política europea "por R. C. M. MOLE (ed.), Basingstoke y Nueva York: Palgrave Macmillan, 2007, Language in Society, 2009, vol. 38, no. 5, págs. 642-643.

12 L. ACKERS, P. DWYER, Leyes fijas, vidas fluidas: el estado de ciudadanía de los migrantes post-jubilación en la Unión Europea, Aging \& Society, 2004, vol. 24, no. 3, págs. 451-475.

13 Consejo de la Unión Europea, Conclusiones del Consejo y de los representantes de los gobiernos de los Estados miembros sobre la integración de los nacionales de terceros países que residen legalmente en la UE, Bruselas, 9 de 
integración de nacionales de terceros países"14 y "Nueva Agenda de Capacidades para Europa" $"$, así como a varios actos del Parlamento Europeo ${ }^{16}$.

\section{CONCEPTUALIZAR LA IDENTIDAD EUROPEA CONTRA EL TRASFONDO DE LA MIGRACIÓN}

La pregunta más importante que plantean muchos estudiosos es: ¿Qué es la identidad europea? En palabras de un ciudadano de la UE, las preguntas podrían ser: ¿Qué me hace europeo? La respuesta a esta pregunta es importante desde una perspectiva individual, pero también afecta las políticas de los Estados miembros y las políticas de la UE como organización supranacional. Esta cuestión, por ejemplo, también surge en el curso del debate sobre el grado de soberanía que los Estados miembros transfieren a la UE. Si bien parte de las sociedades europeas es pro-Unión Europea, algunos insisten en que si una identidad nacional claramente sentida es eclipsada demasiado rápido por una identidad europea (a veces también llamada identidad paneuropea, a menudo percibida como distante o incluso fantasiosa), la se pueden esperar consecuencias.

Entonces, ¿qué se entiende exactamente por "ser europeo"? En uno de sus discursos, un europeo por excelencia, Václav Havel, expresidente de la República Checa, remarcó en 2020:

"Era tan obvio y naturalmente europeo que ni siquiera lo pensé. Y estoy seguro de que eso se aplica a la mayoría de los europeos. Son profundamente europeos, pero ni siquiera lo saben, no se cuelgan esa etiqueta al cuello, por eso las encuestas de opinión muestran que les sorprende un tanto tener que gritar su europeísmo a las alturas. No parece haber una gran tradición de europeísmo considerado en Europa. Eso no es necesariamente algo bueno, y acojo con satisfacción el hecho de que nuestro europeísmo esté empezando a emerger hoy claramente del vasto crisol de conceptos, que hablan por sí mismos. Cuestionarlo, considerarlo y tratar de definirlo, nos ayuda enormemente a comprendernos a nosotros mismos"17.

En el mundo multicultural y multifacético en el que vivimos, la capacidad de percibir la propia identidad es un requisito previo para la coexistencia pacífica con otras identidades. Pensar en el europeísmo significa preguntarse qué conjunto de valores, idea-

diciembre de 2016, (OR. En), 15312 / 16, accesible < $\underline{\text { https://data.consilium.europa.eu/doc/document/ST-15312- }}$ 2016-INIT/en/pdf> (11 de mayo de 2021).

14 Comisión Europea, Comunicación 'Plan de acción sobre la integración de nacionales de terceros países', Bruselas, 7.6.2016, COM (2016) 377 final, accesible en < https://ec.europa.eu/home-affairs/sites/default/files/what-we-do/ policies/european-agenda-migration/paquete-de-implementación-de-propuestas/docs/20160607/communication action plan integration third-country_nationals_en.pdf $>$ (11 de mayo de 2021).

15 Comisión Europea, Comunicación, "Una nueva agenda de competencias para Europa”. Trabajando juntos para fortalecer el capital humano, la empleabilidad y la competitividad ", Bruselas, 10.6.2016, COM (2016) 381 final, accesible en $<$ https://eur-lex.europa.eu/legal-content/EN/TXT/?uri=CELEX:52016DC0381 $>$ (11 de mayo de 2021).

16 Ver Dictamen del Comité Económico y Social Europeo sobre la Integración de los refugiados en la UE, la Resolución del Parlamento Europeo de 5 de julio de 2016 sobre refugiados: inclusión social e integración en el mercado laboral, y Dictamen del Comité de las Regiones ', Comisión para el «Plan de acción sobre la integración de los nacionales de terceros países» en materia de ciudadanía, gobernanza, asuntos institucionales y exteriores.

17 Václav Havel, Discurso en el Parlamento Europeo, 16.2.2000, accesible en $<\underline{\mathrm{https}} / / /$ www.europarl.europa.eu/ sides/getDoc.do?pubRef=-//EP//TEXT+CRE+20000216+ITEM-012+DOC+XML+V0//EN $>(14.3 .2021)$ 
les o principios pertenecen en la mente de un individuo a la noción de Europa, o qué es típico de Europa. Más que eso, también significa partir de la esencia misma de la identidad, examinando todo el concepto de manera crítica. Dibujar los bocetos de la identidad significa definirse en relación con los demás y, también, evaluar las propias fortalezas y debilidades. Jenkins analiza la construcción de la identidad y demuestra cómo se materializa como resultado de la interacción entre la autoidentificación y la categorización externa en varios entornos sociales ${ }^{18}$. Se podría argumentar, como lo hizo Václav Havel, que la idea de conceptualizar y definir el europeísmo ha llegado demasiado tarde, que la integración cultural y política y la introspección deberían haber precedido a la integración económica en la UE.

Los valores europeos comunes, no los beneficios económicos, deberían estar en el centro. Si adoptamos los beneficios de la integración económica como punto de partida, podríamos acabar sacrificando los principales valores europeos. Estos son el respeto de la persona y sus libertades, sus derechos y su dignidad, el principio de solidaridad, la igualdad ante la ley, el estado de derecho, la protección de los derechos de las minorías, el funcionamiento sobre la base del pluralismo político y representativo. democracia, separación de los poderes legislativo, ejecutivo y judicial, respeto por la propiedad privada y la libre empresa, economía de mercado y desarrollo de la sociedad civil ${ }^{19}$. El contenido que tienen estos valores en la actualidad refleja innumerables experiencias europeas modernas, incluido el hecho de que nuestro continente se está convirtiendo en una importante encrucijada multicultural.

El objetivo clave de todo el proyecto de la UE es la solidaridad en un doble sentido: a nivel de los Estados miembros de la UE y a nivel de la UE. La solidaridad genuina entre ciudadanos, residentes, grupos sociales, comunidades y regiones es la mejor base para la solidaridad que no puede dispensarse a nivel estatal. Y en la UE, que debe funcionar como un instrumento de solidaridad, las verdaderas bases civiles deben ser aún más sólidas y prósperas. Por tanto, la viabilidad de la UE depende principalmente, quizás sobre todo, del espíritu con el que sus ciudadanos aceptan una identidad europea.

La capacidad de aceptar a los demás, incluidos los de diferentes nacionalidades y orígenes, es uno de los componentes de la identidad europea, especialmente subrayado en las últimas décadas. Europa gira en gran medida en torno a la migración y los movimientos transfronterizos son su característica natural. La diversidad racial y cultural, el pluralismo y la apertura forman parte del debate actual sobre la identidad europea que requiere repensar los prejuicios y aceptar la diversidad. No hay duda de que las migraciones fueron y siguen siendo la clave para comprender el sentido profundo de Europa en general y de la Unión Europea en particular.

\section{MIGRACIÓN Y FAMILIAS TRANSFRONTERIZAS}

La historia de las migraciones en suelo europeo se ha reflejado en la historia de las relaciones humanas, especialmente con las familias. Tanto las migraciones internas como externas de mayor intensidad en los últimos tiempos son la realidad y la fortuna de la

18 Ver p. Ej. R. JENKINS, Social identity, 4 a ed., 2014 Routledge, p. 6.

19 Véase la Carta de los Derechos Fundamentales de la Unión Europea, DO C 326 de 26.10.2012, p. 391-407. 
UE. También lo son las familias transfronterizas. Estas familias ya son muy comunes y están ampliamente aceptadas en las sociedades europeas. Lamentablemente, pero naturalmente, algunas parejas transfronterizas se separan al final y, en este punto, su naturaleza transfronteriza podría dificultarles lidiar con las consecuencias legales de las mismas ${ }^{20}$.

En este sentido, es muy positivo que la UE, promoviendo el movimiento transfronterizo de personas a través de su libre movimiento de personas como una de sus libertades fundamentales y otras políticas e instrumentos, también haya tomado medidas para ayudar a las parejas transfronterizas. en caso de que su relación falle. Con este fin, se adoptaron un número considerable de instrumentos de la UE. El corpus del derecho de familia internacional privado europeo constituye la base para abordar los diversos desafíos a los que se enfrentan las parejas transfronterizas. Los Reglamentos gemelos que se analizan en este volumen son pilares importantes para establecer un marco legal claro para las parejas cuya separación deberá ser tratada ante los tribunales u otras autoridades competentes de los Estados miembros de la UE. Adoptando la diversidad de leyes nacionales, estos instrumentos allanan un camino unido de la UE no solo hacia la resolución de las relaciones de propiedad familiar legalmente relevantes, sino también hacia la identidad europea como la identidad para la cual la migración y el cruce de fronteras son nada menos que esenciales.

20 Véanse en particular los capítulos 1 y 2 de este volumen. 